\title{
Evaluation of positive emotion in children mobile learning application
}

\author{
Magrizef Gasah', Aslina Baharum², Nurul Hidayah Mat Zain ${ }^{3}$, Suhaida Halamy4 ${ }^{4}$ Rozita Hanapi ${ }^{5}$, \\ Noorsidi Aizuddin Mat Noor ${ }^{6}$ \\ ${ }^{1,2}$ Faculty of Computing and Informatics, Universiti Malay sia Sabah, Malaysia \\ ${ }^{3}$ Faculty of Computer and Mathematical Sciences, Universiti Teknologi MARA (UiTM) Melaka, Malaysia \\ ${ }^{4,5}$ Faculty of Business Management, Universiti Teknologi MARA, Malaysia \\ ${ }^{6}$ Faculty of Built Environment and Surveying, Universiti Teknologi Malay sia, Malaysia
}

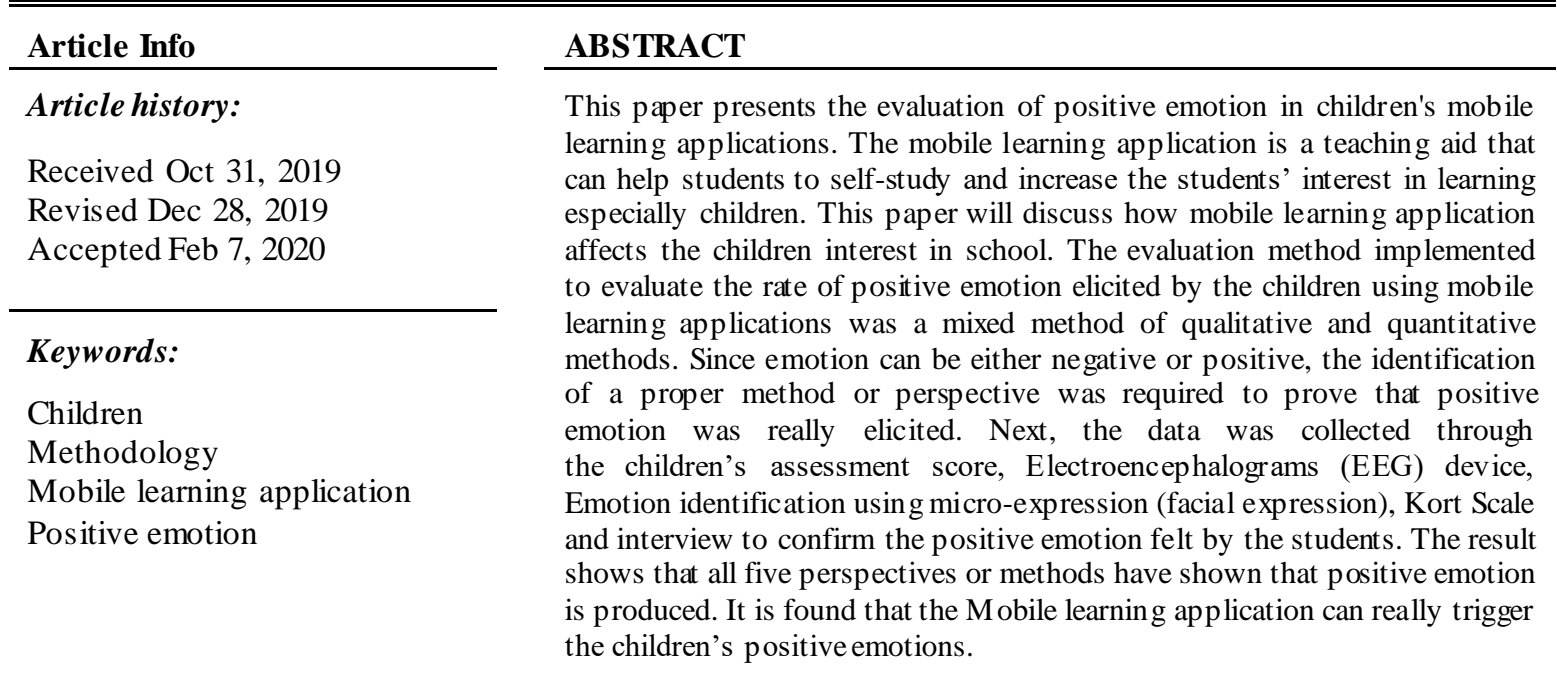

This is an open access article under the $\underline{C C B Y-S A}$ license.

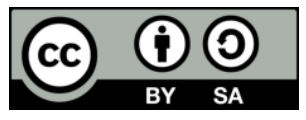

\section{Corresponding Author:}

Aslina Baharum,

Faculty of Computing and Informatics, Universiti Malaysia Sabah, 88400 Kota Kinabalu, Sabah, Malaysia.

Email: aslina@ums.edu.my

\section{INTRODUCTION}

In study on human behaviour it has been suggested that creating positive associations in learning was more effective than the negative ones [1]. The positive emotion felt by the students are beneficial in encountering student's academic challenges. Moreover, the positive emotion can be implemented in mobile learning application to spark the emotional engagement among students [2]. Besides, there is a clear consensus in the psychological and educational fields that a variety of positive emotions play critical roles in fostering learning and mental growth in children [3-4]. Mobile technologies have become an integral part of people's daily life that showed a significant progress in its development within recent years [5]. Nowadays, the m-learning (Mobile Learning) has become the attention and focus of several scientists and work on its development and distribution from all over the world [6-8]. The mobile learning term denotes the use of mobile applications installed on a mobile device (tablet or smartphone) that used in the education process at school [9-10]. The implementation of this mobile learning is not a simple process when it is for young age students and children's learning. Textbook's author, children (students), parents and teachers 
play an important role in the formation of the children character, interests and social behaviour through learnings' process [11]. Therefore, by applying the M-learning in children education, it's shown a significant contribution for children to build their character, behaviour and interest in learning. This could be done by developing an e-learning application that could run on an Android device platform.

According to Desmet (2007), it was possible to design products that target specific types of emotions by measuring emotional responses [12]. The products that excite user will be more successful than those that do not has been supported by consumers and researchers [13]. According to Ashby \& Johnson (2013), exploration of other senses or emotional connection, associations and experience we re important for the product to compete [14]. The link between attachment and emotional design was important for the user to use the product [15]. During the development of the product, the contrasting and categorization of emotions describes how the emotions are correlated to each other. According to Barrett (2006), humans experience emotion through evidence that influence action, thoughts and behaviour.

The research also suggested that emotion can be categorized into various affect related to the human current situation [16]. Next, the emotions can be categorized by identify ing the most basic level of human emotion [17]. This was then supported by Robinson (2008), that identify ing the basic emotion and its definition was required to the classification of emotion into positive and negative emotion [18]. This method was already used in researches such as [19-20]. Unfortunately, classifying the emotions into positive and negative emotion was not easy if the basic level of human emotion was not identified. Therefore, before the emotion can be evaluated, researcher need to understand what kind of emotion that can be considered positive and negative.

Students that prone to positive emotions may experience high levels of achievement partly because such emotions are associated with high-quality peer and teacher relationships [21]. By adapting the positive emotion in learning, this process may improve student learning, achievement, and self-efficacy [22]. This prove that the positive emotion is directly proportional to the student achievement score. Other than that, micro-expressions (facial expression) contain a significant and effective amount of information regarding the true emotions which useful in practical applications such as security and interrogations [23]. This micro-expression (facial expression) was used to identify the children true emotion whether positive or negative emotion. The basic set of emotions is largely discussed but is not defined completely. (Kort et al., 2002) constructed a scale of emotions related to learning ranging from negative to positive states (from -1 to +1 ) that was used in this research to scale the emotion felt by the children [24]. In addition, Electroencephalograms (EEG) record the electric activity of a human's brain through electrodes that are attached to the scalp. According to (Ramirez, 2012) this device could detect and classify the emotion signal from brain wave with high accuracy [25]. Now, there are plenty of EEG device already available in market to detect the human emotion.

Therefore, the evaluation of positive emotion in children mobile learning application help researchers to understand whether there are positives emotion triggered while the children using the application or not. The method used to evaluate such uncertainty was mix method of qualitative and quantitative method. The result of the evaluation helps the researchers and teachers to distinguish a successfullearning application that can be used among the children.

\section{RESEARCH METHOD}

A mobile learning application (Sains Awal PraSekolah) that already been developed was used in this research and an appropriate questionnaire was created. The mobile learning application was evaluated using three (5) different method that can express the participant's real positive emotion after the participant used the application. In order to achieve that all aspects need to be considered like the effectiveness of the mobile learning application in giving the participant's information such as the participant's assessment score, the participant facial expression and their emotions. Moreover, the evaluation continued using electroencephalogram (EEG) device, evaluation using universal facial expression and evaluation using Kort's Scale and interview on participant emotion after using the mobile learning application. After the data have been collected it then being analyzed. The data collection flow of this study was as follow see Figure 1.

Figure 1 show the research method on how the evaluation of the positive emotion have been conducted. Firstly, a Mobile learning application must be selected that act as an object that being tested whether it can produce a positive or negative emotion to the participant. Next, a questionnaire prepared that according to the evaluation test in the data collection. Finally, the data that have been collected are analyzed according to its frequency and mean. The result of the data analysis shown in the next section. 


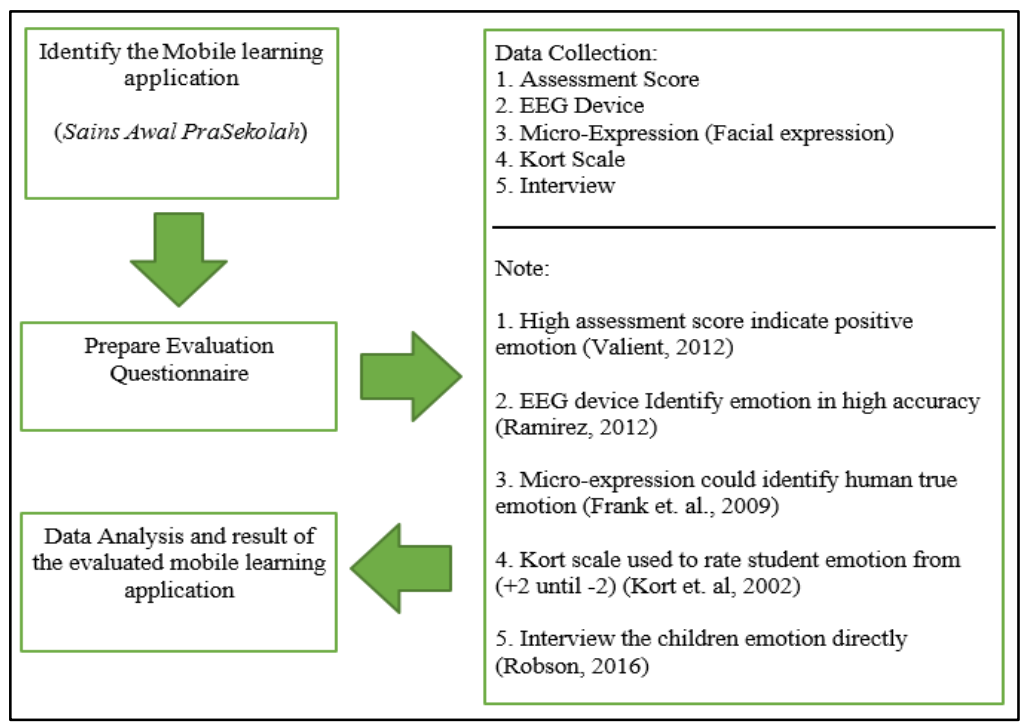

Figure 1. Methodology of the positive emotion evaluation

\section{RESULTS AND ANALYSIS}

The evaluation of the mobile learning application was conducted in three different locations based on its sociology and economy. This to confirm whether that the mobile learning application could be used in a different level of technology exposure or not. The evaluation was conducted at a different location in Sabah that includes rural school (Tadika Advent Goshen Kota Marudu), suburban school (Pacos Trus Penampang) and urban school (Pusat Minda Lestari UMS Kota Kinabalu). There is a total of 104 participants that involve in the evaluation that consists of 98 children Table 1 and six teachers Table 2.

Table 1 . The demography of data collected for children

\begin{tabular}{ccccccc}
\hline \multirow{2}{*}{ Question } & \multirow{2}{*}{ Range } & \multicolumn{4}{c}{ Frequency } & \multirow{2}{*}{ Nercentage } \\
\cline { 3 - 6 } & & Rural & Suburban & Urban & Total & \\
\hline \multirow{3}{*}{ Gender } & Male & 25 & 12 & 15 & 52 & 53.1 \\
& Female & 22 & 10 & 14 & 46 & 46.9 \\
& Total & $\mathbf{4 7}$ & $\mathbf{2 2}$ & $\mathbf{2 9}$ & $\mathbf{9 8}$ & $\mathbf{1 0 0}$ \\
\hline
\end{tabular}

Table 2. The demography of data collected for teacher

\begin{tabular}{ccccccc}
\hline \multirow{2}{*}{ Question } & \multirow{2}{*}{ Range } & \multicolumn{4}{c}{ Frequency } & \multirow{2}{*}{ Percentage } \\
\cline { 3 - 6 } & & Rural & Suburban & Urban & Total & \\
\hline \multirow{2}{*}{ Gender } & Female & 2 & 2 & 2 & 6 & 100 \\
& Total & $\mathbf{2}$ & $\mathbf{2}$ & $\mathbf{2}$ & $\mathbf{6}$ & $\mathbf{1 0 0}$ \\
\hline
\end{tabular}

\subsection{Assessment score}

The assessment score is the quiz mark answered by the children in the e-learning application. The quiz aim is to test the children understanding the topic taught and the score is in percentage value. Three of the highest score in the quiz is recorded according to location and gender as shown in Table 3, Table 4 and Table 5.

Table 3. Mean score of assessment for children at "Tadika Advent Goshen"

\begin{tabular}{ccccccc}
\hline Participants & Questions & N & Minimum & Maximum & Mean & Std. Deviation \\
\hline \multirow{3}{*}{ Rural Children } & Mark 1 (\%) & 47 & 25.00 & 100.00 & 93.94 & 14.07 \\
& Mark 2(\%) & 47 & 50.00 & 100.00 & 93.79 & 13.04 \\
& Mark 3(\%) & 47 & 75.00 & 100.00 & 97.36 & 7.07 \\
& Total Mean & & 50.00 & 100.00 & 95.03 & 11.39 \\
\hline
\end{tabular}

The mean scores of assessments for rural children are presented in Table 3 . The result showed that the mark of three questions was recorded in percentage. This to ensure that the data collected was accurate 
since it's involving the children assessment score. The average minimum mark scored for all the question was $50.0 \%$ and the highest was $100.0 \%$. This indicated that there were still a few children that do not perform well even though using the mobile application because the minimum mark scored was as low as $25.0 \%$. In addition, the total average mean scored by the rural children was $95.0 \%$ with the standard deviation of 11.39. This shown that, most of the children still can perform well with such standard deviation.

The mean scores of assessments for suburban children are shown as Table 4 . The result showed that the average minimu m mark scored for all the question was $60.0 \%$ and the highest was $100.0 \%$. This indicated that the children level of understanding was moderate and some of them can perform well using the mobile application. In addition, the total average mean scored by the suburban children was $95.4 \%$ with the standard deviation of 11.54. This result shown that, the suburban children can perform almost the same with the rural children despite the children level of technology exposure.

Table 4. Mean score of ass essment for children at "Pacos Trust"

\begin{tabular}{ccccccc}
\hline Participants & Questions & $\mathrm{N}$ & Minimum & Maximum & Mean & Std. Deviation \\
\hline \multirow{2}{*}{ Suburban } & Mark 1(\%) & 22 & 50.00 & 100.00 & 95.91 & 11.82 \\
Children & Mark 2(\%) & 22 & 80.00 & 100.00 & 96.50 & 7.62 \\
& Mark 3(\%) & 22 & 50.00 & 100.00 & 93.77 & 15.17 \\
& Total Mean & & 60.00 & 100.00 & 95.39 & 11.54 \\
\hline
\end{tabular}

The mean scores of assessments for urban area children are presented in Table 5. The results showed that the average minimum mark scored for all the question was $71.7 \%$ and the highest was $100.0 \%$. This indicated that the children level of understanding was almost excellent and can perform well using the mobile application. In addition, the total average mean scored by the urban children was $97.2 \%$ with the standard deviation of 7.48. This result shown that, the urban children can perform very well using the application. This prove that the children familiarity with the current technology enable the children to perform very well with the assessment score evaluation. The assessment score shows that the average of children can score $95.0 \%$ in rural area, $95.4 \%$ for the suburban area and $97.2 \%$ in urban area. This shows that the urban children can score more than the child ren in rural and in suburban area. Moreover, the average of those 3 areas can score about $95.9 \%$ with 10.14 standard deviations. This proves that the children can understand the learning materials given and can perform well with the quiz. This also prove that the mobile application can produce a positive experience to children almost $95.0 \%$.

Table 5. Mean score of assessment for children at "PML UMS"

\begin{tabular}{ccccccc}
\hline Participants & Questions & N & Minimum & Maximum & Mean & Std. Deviation \\
\hline \multirow{3}{*}{ Urban Children } & Mark 1 (\%) & 29 & 75.00 & 100.00 & 95.28 & 9.53 \\
& Mark 2(\%) & 29 & 60.00 & 100.00 & 97.07 & 9.21 \\
& Mark 3(\%) & 29 & 80.00 & 100.00 & 99.31 & 3.71 \\
& Total Mean & & 71.67 & 100.00 & 97.22 & 7.48 \\
\hline
\end{tabular}

\subsection{Electroencephalograms device}

The Electroencephalogram (EEG) device capable of recording the brain activity in real time and shows the learning effectiveness. According to [26], the positive emotion felt by the student is directly proportional to the level of learning effectiveness. Therefore, the EEG device could be used as an evaluation method to identify the level of positive emotion felt by the children. According to Gasah (2018), child ren focus, and attention are only between three to five minutes [27]. Since the average of children attention only between three to five minutes, the data between that period only, will be considered for evaluation because children were in their full attention during that period. Table 6, Table 7 and Table 8 shows the result of the EEG. The percentage value represents the positive and negative emotion felt by the children less than fifty per cent $(<50 \%)$ means negative emotion and more than fifty per cent $(>50 \%)$ means positive emotion.

Table 6 shows the EEG device score for rural children. The score of the EEG device for less than 3 minutes indicate that almost $51.5 \%$ of effectiveness in children from 7 children only. The mean increases to $53.2 \%$ when the period was less than 5 minutes taken from 25 children. This result contradicts from the expected result because the effectiveness of learning should be decreased when the time increases.

Table 7 shows the EEG device score for suburban children. The score of the EEG device for less than 3 minutes indicate that almost $82.2 \%$ of effectiveness in children from seven children. This then shows a significantly decreasing to $74.4 \%$ when the period is less than 5 minutes were taken from 10 children. This result followed the prediction of the result in phase one where the effectiveness in learning will be 
decreasing to time. Even though, the level of high level of effectiveness that reaches more than $82.0 \%$ show that the mobile learning application in this area could build a positive emotion to children.

Table 6. EEG device score at "Tadika Advent Goshen"

\begin{tabular}{ccccccc}
\hline \multicolumn{7}{c}{ Rural Kids (Kota Marudu) } \\
\hline Minute & & N & Minimum & Maximum & Mean & Std. Deviation \\
\hline <3 Mins & Time (mm:ss) & 7 & $1: 38$ & $2: 55$ & $2: 22$ & 0.02 \\
& Percentage (\%) & 7 & 24.2 & 67.2 & 51.357 & 16.52 \\
& Valid N (listwise) & 7 & & & & \\
<5 Mins & Time (mm:ss) & 25 & $1: 38$ & $4: 47$ & $3: 24$ & 0.03 \\
& Percentage (\%) & 25 & 24.2 & 95 & 53.208 & 19.68 \\
& Valid N (list wise) & 25 & & & & \\
\hline
\end{tabular}

Table 7. EEG device score at "Pacos Trust"

\begin{tabular}{lcccccc}
\hline \multicolumn{7}{c}{ Suburban Kids (Penampang) } \\
\hline Minute & & N & Minimum & Maximum & Mean & Std. Deviation \\
\hline <3 Mins & Time (mm:ss) & 7 & $0: 36$ & $2: 51$ & $1: 53$ & 0.04 \\
& Percentage (\%) & 7 & 68.3 & 100 & 82.186 & 11.18 \\
& Valid N (list wise) & 7 & & & & \\
$<5$ Mins & Time (mm:ss) & 10 & $0: 36$ & $4: 35$ & $2: 35$ & 0.06 \\
& Percentage (\%) & 10 & 39.8 & 100 & 74.41 & 18.13 \\
& Valid N (list wise) & 10 & & & & \\
\hline
\end{tabular}

Table 8 shows the EEG device score for suburban children. The score of the EEG device for less than 3 minutes indicate that almost $78.7 \%$ of effectiveness in child ren were taken from three children only. This then shows a significantly decreasing to $61.752 \%$ when the period is less than 5 minutes were taken from 21 children. This result followed the prediction of the result in phase one where the effectiveness in learning will be decreasing to time. Even though, the level of high level of effectiveness that reaches more than $78.0 \%$ show that the mobile learning application in this area could build a positive emotion to children. The EEG device score shows that the average percentage of children having positive emotion in less than three-minute study for rural children (51.4\%), suburban children $(82.2 \%)$ and urban children $(78.7 \%)$. This show that the e-learning application is more effective in creating a positive emotion in suburban children compared to urban children and rural children. Next, the study duration that more than three minute and less than five minutes show an increment for rural children $(53.2 \%)$ and decrement to suburban children $(74.4 \%)$ and urban children $(61.8 \%)$ respectively. This proves the findings in phase 1 that the children learning efficiency will decrease with in time because of two out of three schools shown the effectiveness decrement. Finally, the average of the 3 areas could EEG score for less than three minutes is $70.7 \%$ with standard deviation of 13.087 and less than five minute is $63.1 \%$ with standard deviation of 19.444 . The result of the EEG score also shown that the application could create more positive emotion than the native emotion.

Table 8. EEG device score at "PML UMS"

\begin{tabular}{ccccccc}
\hline \multicolumn{7}{c}{ Urban Kids (Kota Kinabalu) } \\
\hline Minute & & $\mathrm{N}$ & Minimum & Maximum & Mean & Std. Deviation \\
\hline <3 Mins & Time (mm:ss) & 3 & $2: 06$ & $2: 59$ & $2: 27$ & 0.02 \\
& Percentage (\%) & 3 & 71.4 & 92 & 78.667 & 11.56 \\
& Valid N (list wise) & 3 & & & & \\
<5 Mins & Time (mm:ss) & 21 & $2: 06$ & $4: 56$ & $3: 59$ & 0.03 \\
& Percentage (\%) & 21 & 29.9 & 94 & 61.752 & 20.52 \\
& Valid N (list wise) & 21 & & & & \\
\hline
\end{tabular}

\subsection{Micro-expression}

The facial expression is also known as the micro expression. According to Ekman (2004) it is difficult to fake a micro expression because it is an involuntary facial expression that appears on a person's face according to the emotions being experienced [28]. There is consist of 7 universal micro-expression: sadness, anger, fear, disgust, contempt, surprise and happy. Therefore, by identifying the facial expression of the children, their emotion could be identified. Figure 2, Figure 3 and Figure 4 show the result of the facial expression and its emotion. The result sorted based on gender and the presence of a facial expression that shows emotion. Figure 2 shows the facial expression result of rural children. The result of the micro- 
expression (facial expression) graph indicated that most of the rural children leading towards happiness (19 children) and surprise (18 children). This facial expression proved that the children produce more positive emotion in facial expression compared to negative emotion.

Figure 3 shows the facial expression result of suburban children. The result of the micro-expression (facial expression) graph indicated that most of the suburban children was happy (13 children) and surprise (11 children). This proves that the suburban children were mostly happy and surprise that indicated positive emotion when using the mobile application.

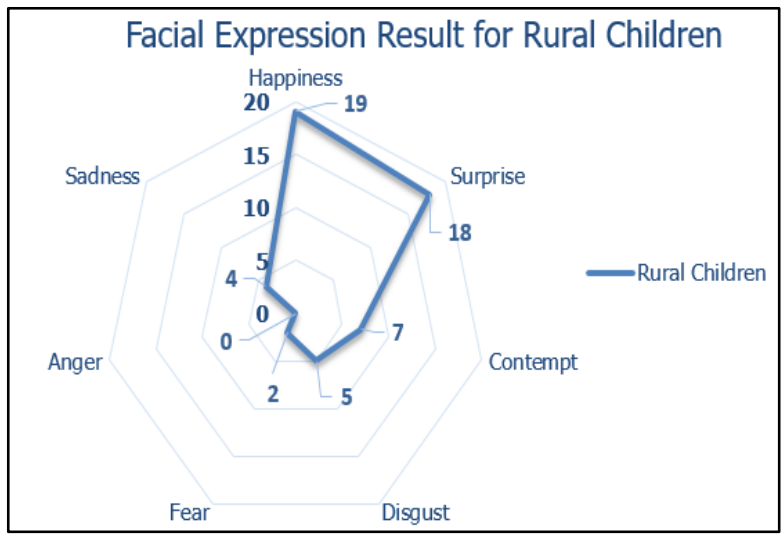

Figure 2. The facial expression result of rural children

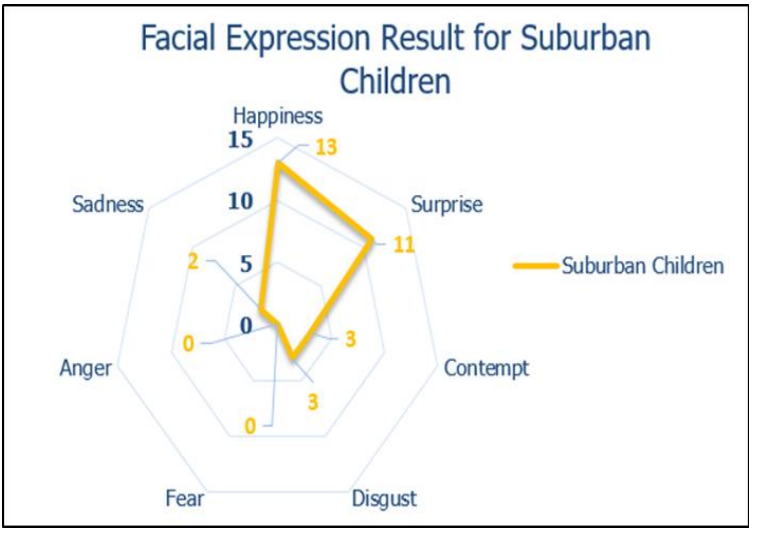

Figure 3. The facial expression result of suburban children

Figure 4 shows the facial expression result of urban children. The result of the micro-expression (facial expression) graph indicated that most of the urban children leading towards happiness (14 children) and surprise (12 children). This facial expression proved that the urban children produce more positive emotion in facial expression compared to negative emotion. The graph for all of the area shows a significantly high frequency towards the positive emotion (Happiness and Surprise) for all of the child ren compared to the negative e motion (Sadness, Anger, Disgust, Fear, and Contempt). The result from the micro expression (facial expression) shows that $72.9 \%$ of the participant show positive emotion feedback when using the mobile application and only $27.1 \%$ of the participants show negative emotion feedback. This proves that the mobile application can give positive emotion to participants almost $73.0 \%$.

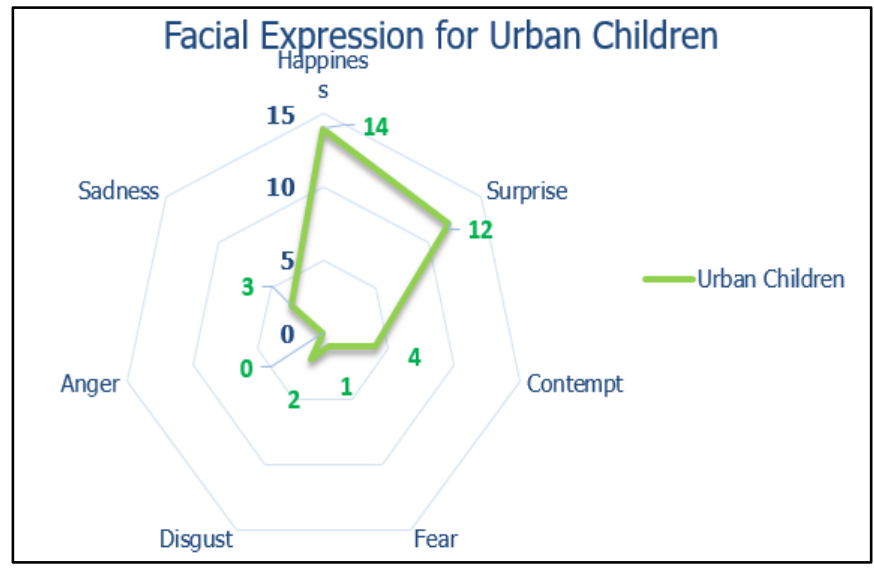

Figure 4. The facial expression results urban children

\subsection{Kort scale}

The Kort scale evaluation aims to identify the user experience whether the participant like it or not. The scale range is from $(+2,+1,0,-1,-2)$ where +2 means very likely, and -2 not likely. The evaluation includes the content, educational, appearances and organization of the e-learning application. Figure 5 shows 
the result from the Kort scale rating where most of the participants rate +2 for content, educational, appearances and organization of the mobile application whereby having the percentage of $66.4 \%, 70.2 \%$, $80.8 \%$ and $71.2 \%$ respectively.

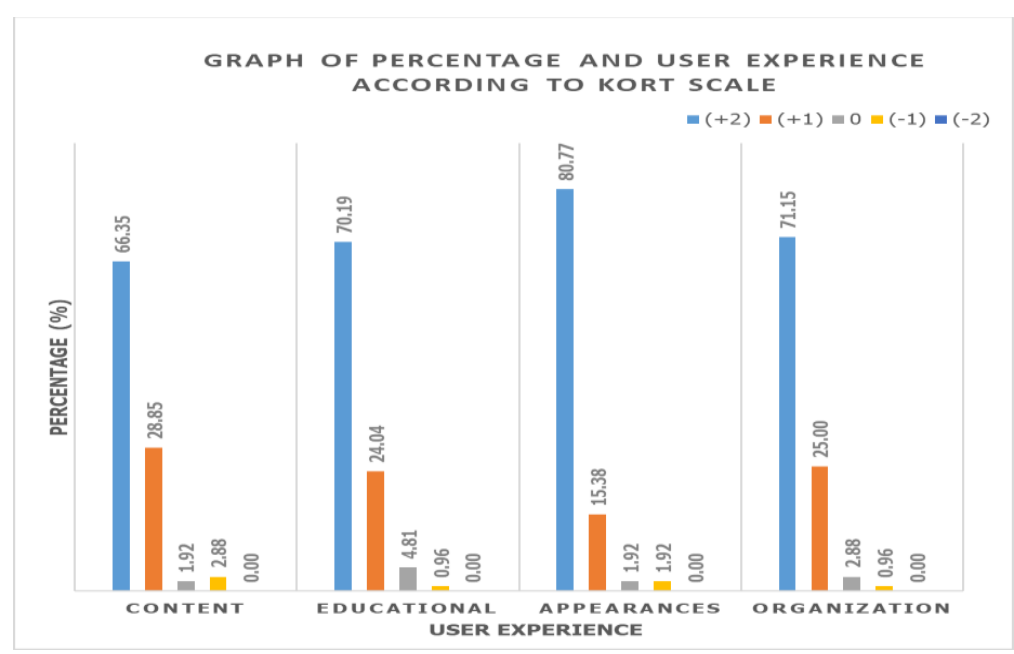

Figure 5. Graph of percentage and user experience according to kort scale rating

\subsection{Interview}

The expected outcomes in this research before its evaluation is to have user or children feel positive emotion toward learning and school. This positive emotion will give the children positive experience in learning that could increase the interest to go to school among children. The evaluation of the mobile learning application was executed using 4 method where it is highly reliable and have been used by a lot of researchers. Table 9 shows that the result of all of the evaluation method shown that the mobile learning application could create a positive experience to user that leads to the production of positive emotion more than $70.0 \%$ and prove that the mobile learning application was successful in creating the children interest in learning. Other than that, in order to confirm whether the e-learning application really could solve the problem in this research, which is to make the children interested in school, three extra interview question was asked to the participants.

Table 9. Summary of the mobile learning application evaluation result

\begin{tabular}{ccc}
\hline Type of & \multicolumn{2}{c}{ Result } \\
\cline { 2 - 3 } Evaluation & Negative Emotion & PositiveEmotion (\%) \\
\hline EEGDevice & 29 & 71 \\
Kort Scale & 28 & 72 \\
Assessment score & 5 & 95 \\
Facial Expression & 27 & 73 \\
\hline
\end{tabular}

Table 10 show that the result of the three interviews. The result from the interview shows that $90.4 \%$ of the participants feel positive after using the application. Next, $97.1 \%$ of the participants like to go to school when the application is implemented in their school. Lastly, $80.4 \%$ of the participants would like to recommend the application to their friends.

Table 10. Result of interview question based on their experience

\begin{tabular}{lccc}
\hline \multicolumn{1}{c}{ Interview Question } & Response & $\mathrm{N}$ & Percentage \\
\hline Interview 1 & Yes & 94 & 90.38 \\
(Feel a positive emotion after use the application) & No & 10 & 9.62 \\
Interview 2: & Yes & 101 & 97.12 \\
(Interested in school after use the application) & No & 3 & 2.88 \\
Interview 3 & Yes & 93 & 89.42 \\
(Recommend the application to friends) & No & 11 & 10.58 \\
\hline
\end{tabular}


Thus, all of the evaluation and interview show a positive result where it verifies the reliability of the research method created. This proves that the approaches used in the research method is capable in creating a positive emotion through mobile learning application to the user. By applying the research method and implement it in the development of mobile learning application in the future, it is possible to put make children more interested to schoolfor learning.

\section{CONCLUSION}

The result of the evaluation of the positive emotion in children Mobile Learning Application from five method used prove that the mobile learning application (sains awal prasekolah) can trigger the positive emotion and positive experience in learning. The result of the evaluation were assessment score ( $95.7 \%$ with 9.545 standard deviations), EEG device (less than three minute is $70.7 \%$ with standard deviation of 13.087), facial expression (positive emotion to participants almost $73.0 \%$ ), Kort scale ( +2 for content, educational, appearances and organization with a total average of $72 \%)$ and interview $(90.4 \%$ of the participants feel positive after using the application). Therefore, the Sains Awal PraSekolah mobile learning can be considered as the successful in projecting the positive emotion to children since all the result was above $70 \%$ for all of its evaluation. Meanwhile, this also proven that the method of the positive emotion was reliable and can be conducted with such significant result.

\section{ACKNOWLEDGEMENTS}

Researchers are thankful to Universiti Malaysia Sabah (UMS) for the support of the resources and necessary facilities for the preparation of the research. This study is currently funded by a UMSGreat Grant from Universiti Malaysia Sabah (GUG0299-2/2018).

\section{REFERENCES}

[1] C. Corradino, Katie Fogarty, "Positive Emotions and Academic Achievement," [Online].Available:https://steinhardt.ny u.edu/app sych/opus/issues/2016/spring/corradino_fogarty, 2018.

[2] C. Wroten, "Emotional Engagement: How Positive And Negative Emotions Affect eLearning,". [Online]. Available: https://elearningindustry.com/emotional-engagement-positive-negative-emotions-affect-elearning, 2015.

[3] R. F. Bornstein, "Exposure and affect: Overview and meta-analysis of research, 1968-1987," Psychol. Bull., vol. 106 , no. 2 , pp. $265-289,1989$.

[4] R. M. Foley, "Academic Characteristics of Incarcerated Youth and Correctional Edu-cational Programs: A Literature Review," J. Emot. Behav. Disord, vol. 9, no. 4, pp. 248-259, Oct. 2001.

[5] M. Sarwar and T. R. Soomro, "Impact of Smartphone's on Society," Eur. J. Sci. Res., vol. 98, no. 2, pp. 216-226, 2013.

[6] G. Botzer and M. Yerushalmy, "Mobile application for mobile learning," in Proceed-ings of IADIS International Conference on Cognition and Exploratory Learning in Dig-ital Age (CELDA 2007), pp. 7-9, 2007.

[7] D. Dochev and I. Hristov, "Mobile learning applications ubiquitous characteristics and technological solutions," Bulg. Acad. Sci. Cybern. Inf. Technol, vol. 6, no. 3, 2006.

[8] R. Kraleva, V. Kralev, and D. Kostadinova, "A conceptual design of mobile learning applications for preschool children," arXiv Prepr. arXiv1606.05753, 2016.

[9] S. M. Hsu, S. F. Wang, Y. J. Hsieh, C. C. Cheng, and Y. J. Liao, "The physical and bi-omedical characteristics of the novel transmission type X-ray equipment," Radiat. Meas., vol. 90, pp. 238-241, 2016.

[10] D. Parsons, H. Ryu, and M. Cranshaw, "A design requirements framework for mobile learning environments," $J C P$, vol. 2, no. 4, pp. 1-8, 2007.

[11] J. S. Eccles, "Influences of parents' education on their children's educational attain-ments: The role of parent and child perceptions,"London Rev. Educ., vol. 3, no. 3, pp. 191-204, 2005.

[12] Desmet, P. M. A., Porcelijn, R., \& Dijk, M. B. Van, "Emotional Design ; Application of a Research-Based Design Approach," Spinger Link, pp. 141-155, 2007.

[13] Millard, N. "Learning from the "wow' factor-how to engage customers through the design of effective affective customer experiences," BT Technology Journal, vol 24, no. 1, pp. 11-16, 2016.

[14] Ashby, M. F., \& Johnson, K., "Materials and design: the art and science of material selection in product design," Butterworth-Heinemann, 2013.

[15] Smith, P, "Design for Collaborative Consumption", Retrieved from , https://www.ntnu.no/documents/139799/1273574286/TPD4505.Phil.Smith.pdf/6a94bebf-35c0-4656-91eb84ffa3d9d08f,pp. 1-12, 2008 .

[16] Barrett, L. F, "Solving the Emotion Paradox : Categorization and the Experience of Emotion," Personality and Social Psychology, vol. 10, no. 1, pp. 20-46, 2006.

[17] Edelstein, R. S., \& Shaver, P. R, "A cross-cultural examination of lexical studies of self-conscious emotions," The Self-Conscious Emotions: Theory and Research, 194-208, 2007. 
[18] Robinson, D. L, "Brain function, emotional experience and personality," Netherlands Journal of Psychology, vol. 64 , no. 4 , pp. $152-168,2008$.

[19] Savolainen, R. 2015, "Expressing emotions in information sharing : a study of online discussion about immigration Earlier research," IR Information Research, vol. 20, no. 1, 2015.

[20] Turumugon, P., Aslina, B., Nadia-Hanin, N., Nor-Azida, M.N., Noorsidi-Aizuddin, M.N., \& Emelia, A.R, "Users' emotional evaluation towards kansei-based higher learning institution website using geneva emotion wheel," Indonesian Journal of Electrical Engineering and Computer Science, vol 16, no. 3, pp. 1547-1554, 2019.

[21] C. Valiente, J. Swanson, and N. Eisenberg, "NIH Public Access," vol. 6, no. 2, pp. 129-135, 2012.

[22] S. L. Christenson, A. L. Reschly, and C. Wylie, "Handbook of research on student en-gagement," Springer Science \& Business Media, 2012.

[23] M. O'Sullivan, M. G. Frank, C. M. Hurley, and J. Tiwana, "Police lie detection accu-racy: The effect of lie scenario," Law Hum. Behav., vol. 33, no. 6, paper. 530, 2009.

[24] B. Kort and R. Reilly, "Analytical Models of Emotions, Learning and Relationships : Towards an Affect-sensitive Cognitive Machine," pp. 1-13, 2002.

[25] R. Ramirez and Z. Vamvakousis, "Detecting emotion from EEG signals using the emotive epoc device," in International Conference on Brain Informatics, pp. 175-184, 2012.

[26] R. Pekrun, T. Goetz, W. Titz, and R. P. Perry, "Positive emotions in education.", in Beyond Coping: Meeting Goals, Visions, and Challenge, paper. 149, 2002.

[27] M. Gasah and A. Baharum, "A Conceptual Framework for Emotional Connection towards Mobile learning application Design for Children," vol. 2018, 2018.

[28] P. Ekman, "Emotions Revealed: Understanding Faces and Feelings: Phoenix," 2004. 